\title{
Effect of supratentorial space-occupying lesions on regional intracranial pressure and local cerebral blood flow: an experimental study in baboons ${ }^{1}$
}

\author{
L. SYMON ${ }^{2}$, E. PASZTOR ${ }^{3}$, N. M. BRANSTON, AND N. W. C. DORSCH \\ From the Department of Neurosurgical Studies, The Institute of Neurology, \\ Queen Square, London
}

SYNOPSIS Cortical blood flow and epidural intracranial pressure have been measured in the two supratentorial compartments of the intracranial space in experimental baboons during the acute expansion of a parieto-occipital epidural balloon. Differential pressures between the two halves of the supratentorial space have been found, and these have been associated with evidence that flow has fallen more quickly in the hemisphere most compressed. The evidence points to a more rapid exhaustion of the autoregulatory capacity in the hemisphere subjected to greater compression, a fall in perfusion pressure to below critical autoregulatory levels occurring slightly before that in the opposite hemisphere, and the establishment of a differential flow pattern for a short time during a critical phase of compression. The displacements induced by inflation of the parieto-occipital balloon have been described.

The relationship between the failure of function of nervous tissue and the development of a compressing lesion is of primary interest to the neurosurgeon. Investigation of the pathophysiological processes involved in this relationship has been stimulated increasingly in recent years by development of techniques for the measurement of cerebral blood flow in a regional (Lassen et al., 1963; Høedt-Rasmussen et al., 1966; HøedtRasmussen, 1967) or a focal manner (Aukland et al., 1964; Aukland, 1965), and by the accumulation of data on intracranial pressure obtained either in the clinic using a central cerebrospinal fluid (CSF) space measurement (Lundberg, 1960) or using transducers inserted into the subdural (Hulme and Cooper, 1966; Tindall et al., 1972) or epidural space (Jacobson and Rothballer, 1967; Dorsch et al., 1971; Sundbärg and Nornes, 1972; Symon et al., 1972). It has be-

\footnotetext{
1 The study was supported by the Medical Research Council and by the Wellcome Foundation.

2 Address for reprints: Mr. Lindsay Symon, FRCS, Department of Neurosurgical Studies, The National Hospital, Queen Square, London WC1N 3BG, England.

3 Dr. Pasztor was the recipient of a research fellowship from the Wellcome Foundation. Present address: The Institute of Neurosurgery, 1145 Budapest, Amerikai -u57, Hungary.
}

come clear that the type of neurological dysfunction resulting from a space-occupying lesion is critically dependent not only on the site of the lesion but on the rapidity of its growth. To some extent this is a reflection of the rate at which the lesion crosses the flat or accommodating part of the pressure/volume curve (Langfitt, 1969), but it is only by the accumulation of data acquired by modern methods that a meaningful interpretation of the relationships between circulatory depression secondary to pressure, neurological dysfunction secondary to circulatory impairment, and the origin of tissue shifts within the brain can begin.

The present work was an attempt to relate pressure and flow events occurring in response to rapidly inflated epidural expanding lesions in primates.

\section{METHODS}

Six baboons (Papio cynocephalus or Papio nubius) of either sex, in the weight range $10-15 \mathrm{~kg}$, were used in these experiments. After tranquillization with phencyclidine, they were anaesthetized with a sleep 
chloralose $(60 \mathrm{mg} / \mathrm{kg})$, intubated, and respiration maintained with a Starling pump after immobilization with gallamine triethiodide $(1 \mathrm{mg} / \mathrm{kg}$ repeated as necessary). End-tidal $\mathrm{CO}_{2}$ was continuously monitored with a Beckman gas analyser (model LB1) by sampling from the endotracheal tube. Blood pressure was recorded by a P23G Statham arterial gauge from a femoro-aortic catheter, central venous pressure recorded by a P23V Statham gauge from the superior vena cava via one femoral vein, and a second femoro-aortic catheter introduced for intermittent sampling of arterial blood for analysis in the micro-Astrup apparatus for $\mathrm{pH}, \mathrm{pCO}_{2}$, and $\mathrm{pO}_{2}$. The respirator volume was adjusted to maintain a normal arterial $\mathrm{pCO}_{2}$ between 35 and $45 \mathrm{mmHg}$, and pure oxygen used as the inhalational gas. The animals were then positioned in a Narishige stereotactic apparatus (model SN3) and twist drill holes in the skull made to enable placement of fine platinum electrodes (Symon et al., 1973) in putamen and white matter on both sides, and in frontal and parietal cortex bilaterally. The reference electrode for the hydrogen system was placed subcutaneously in the interscapular region. Four extradural pressure gauges (Dorsch et al., 1971) were placed through $12 \mathrm{~mm}$ trephine holes in both frontal and parietal zones, and a further $12 \mathrm{~mm}$ trephine hole made in the postparieto-occipital zone on the right side. The transducers were held in place with acrylic, and an extradural balloon was introduced to lie in the parieto-occipital zone near the occipital pole of the right hemisphere through the parieto-occipital trephine hole, the dura mater having been stripped. This defect was then closed with acrylic.

The transducers used were similar to those previously used (Corne et al., 1968) with two major modifications. The construction of the present gauges was entirely coplanar, the tip of the sensing arm being on the same plane as the outer and sensitive part of the body, thus eliminating any influence of dural tension (Dorsch and Symon, 1972; Majors et al., 1972). In these gauges also, metal foil rather than semiconductor gauges were used, so that full bridge configuration within the gauge could be employed, with resulting improvement in sensitivity and drift. A spinal needle was introduced into the cisterna magna and connected with a Statham P23 BB pressure transducer for recording of CSF pressure. After a few minutes had been allowed for pressures to stabilize, the extradural pressures were calibrated against cisternal pressure as an extra check, although extradural pressure could be obtained by the substitution of current deflection in a previously made in vitro calibration graph. Extradural pressure calibrated in this way correlated well with cisternal pressure measured at the same time

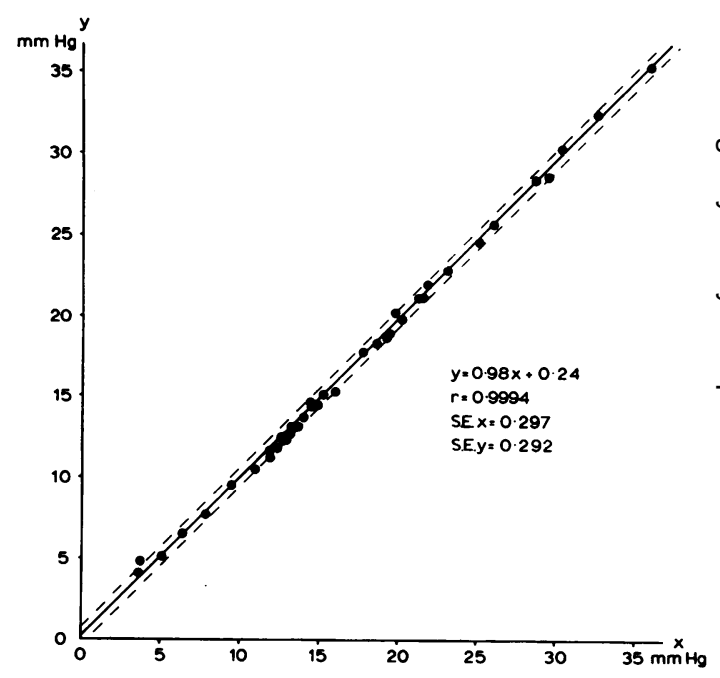

FIG. 1. A comparison of cisternal (x) and extradural (y) pressures in a baboon. Extradural pressures in this graph are predicted from the preliminary in vitro $\omega$ calibration of the transducer, and the $95 \%$ confidence limits are shown.

(Fig. 1), providing that accurate coplanar placemen of the extradural transducer was ensured and excessive dural indentation avoided. As a check. therefore, intracranial pressure was in each case raised by between 30 and $50 \mathrm{mmHg}$ by the inhalation of $\mathrm{CO}_{2}$, and deflection of extradural recordings plotted against simultaneous cisternal pressure measurements during both the rising and falling phases of intracranial pressure. A graph of deflection of extradural pressure against intracranial pressure was then made for use during the latter part of the experiment (Fig. 2). This $\mathrm{CO}_{2}$ calibration was combined with control and test episodes of hydrogen inhalation, $7 \%-10 \%$ hydrogen being introduced into the endotracheal tube for three to four minutes per saturation (Pasztor et al., 1973). Hydrogen clearance was measured for the 10 minutes after the discontinuance of each hydrogen inhalation. Cisternal recording was maintained for as long as possible, but invariably failed in the course of the experiment with the prolapse of the cerebellar tonsils usually at an intracranial pressure exceeding $70 \mathrm{mmHg}$.

The balloon inflated at a constant rate of $0.2 \mathrm{ml} /$ min by a Palmer slow infusion pump, which ran continuously from the start of inflation of the balloon except during episodes of hydrogen clearance, when, in order to avoid irregularities in the intracranial pressure and to minimize systemic blood pressure reactions, the inflation of the balloon was 


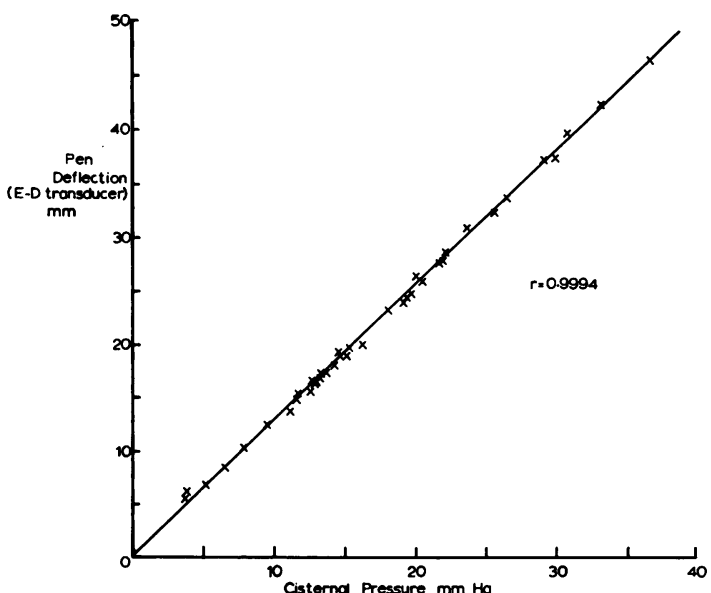

FIG. 2. In vivo calibration of the output of the extradural transducer (expressed as millimetres of pen deflection on a Beckman type $R$ recorder) plotted against cisternal pressure in $\mathrm{mmHg}$. A high degree of correlation is evident $(P<0.001)$.

maintained intermittently to keep the raised level of intracranial pressure at a constant level during hydrogen clearance. Escape of fluid from the balloon was not possible in the course of the experiment.

The outputs of the intracranial pressure transducers and of the systemic blood pressure and CVP monitors were displayed on a Beckman type $R$ polygraph, the outputs of the hydrogen electrodes being recorded on a Rikadenki 4-channel slow recorder (model B4021), each recorder channel sampling two electrodes alternately. The pupillary reactions were recorded by direct examination in the course of a balloon inflation. When inflation of the balloon had been pursued to high levels and very slow clearance was being obtained from both hemispheres, the experiment was terminated in one of two ways. In the first, hyperaemia was induced by suddenly deflating the balloon, and the effect recorded by a further episode of hydrogen clearance (Symon et al., 1973). The balloon was then reinflated with exactly the same volume and the animal killed. In the second, the balloon remained inflated and the animal was killed. Finally, in all experiments, the head of the animal was removed and fixed with the extradural balloon in situ after removal of transducers and electrodes, so that shifts induced by the extradural lesion and mass depression of the occipitoparietal cortex could be examined at leisure.

INTRACRANIAL PRESSURE MEASUREMENTS The data for intracranial pressure measurements, taken during the course of gradually increasing pressure induced by inflation of the extradural balloon, are shown in Table 1 for the four transducers in the six experiments. For the purpose of analysis, four points during the evolution of the experiment have been chosen. The first of these was when the cisternal reference external transducer recorded a pressure of $10 \mathrm{mmHg}$. This was usually slightly into the experiment from baseline but constituted a handy point of

TABLE 1

INTRACRANIAL PRESSURE DATA*

\begin{tabular}{|c|c|c|c|c|c|c|c|c|c|c|c|c|}
\hline \multirow[t]{2}{*}{ ICP level } & & \multicolumn{6}{|c|}{ Experiments } & \multirow[t]{2}{*}{ Mean } & \multirow[t]{2}{*}{$S D$} & \multicolumn{2}{|c|}{ Hemisphere } & \multirow[t]{2}{*}{$P$} \\
\hline & & 1 & 2 & 3 & 4 & 5 & 6 & & & Mean & $S D$ & \\
\hline $\begin{array}{l}\text { Cisternal } \\
\text { pressure } \\
10 \mathrm{mmHg}\end{array}$ & $\begin{array}{l}\mathbf{L} \text { anterior } \\
\mathbf{L} \text { posterior } \\
\mathbf{R} \text { anterior } \\
\mathbf{R} \text { posterior }\end{array}$ & $\begin{array}{r}9 \cdot 0 \\
9 \cdot 5 \\
6 \cdot 5 \\
16 \cdot 0\end{array}$ & $\begin{array}{r}10.0 \\
13 \cdot 0 \\
9 \cdot 5 \\
11 \cdot 0\end{array}$ & $\begin{array}{l}5 \cdot 0 \\
6 \cdot 5 \\
6 \cdot 0 \\
5 \cdot 0\end{array}$ & $\begin{array}{r}8 \cdot 5 \\
10 \cdot 0 \\
10 \cdot 0 \\
12 \cdot 0\end{array}$ & $\begin{array}{r}6 \cdot 0 \\
9 \cdot 0 \\
9 \cdot 0 \\
19 \cdot 0\end{array}$ & $\begin{array}{r}8 \cdot 0 \\
6 \cdot 0 \\
8 \cdot 0 \\
11 \cdot 5\end{array}$ & $\begin{array}{r}7 \cdot 75 \\
9 \cdot 00 \\
8 \cdot 17 \\
12 \cdot 42\end{array}$ & $\begin{array}{l}1 \cdot 89 \\
2 \cdot 55 \\
1 \cdot 63 \\
4 \cdot 78\end{array}$ & $\begin{array}{r}8 \cdot 83 \\
10 \cdot 30\end{array}$ & $\begin{array}{l}2 \cdot 14 \\
3 \cdot 89\end{array}$ & $>0.05$ \\
\hline $\begin{array}{l}\text { Left posterior } \\
\text { extradural } \\
\text { pressure } \\
\mathbf{3 0 ~} \mathbf{m m H g}\end{array}$ & $\begin{array}{l}\mathbf{L} \text { anterior } \\
\mathbf{L} \text { posterior } \\
\mathbf{R} \text { anterior } \\
\mathbf{R} \text { posterior }\end{array}$ & $\begin{array}{l}39 \cdot 5 \\
30 \cdot 0 \\
37 \cdot 5 \\
52 \cdot 0\end{array}$ & $\begin{array}{l}40 \cdot 0 \\
30 \cdot 0 \\
48 \cdot 0 \\
55 \cdot 0\end{array}$ & $\begin{array}{l}29 \cdot 5 \\
30 \cdot 0 \\
28 \cdot 0 \\
37 \cdot 5\end{array}$ & $\begin{array}{l}27 \cdot 5 \\
30 \cdot 0 \\
39 \cdot 0 \\
43 \cdot 0\end{array}$ & $\begin{array}{l}28 \cdot 6 \\
30 \cdot 0 \\
30 \cdot 0 \\
37 \cdot 6\end{array}$ & $\begin{array}{l}27 \cdot 0 \\
30 \cdot 0 \\
32 \cdot 5 \\
33 \cdot 0\end{array}$ & $\begin{array}{l}32 \cdot 02 \\
30 \cdot 00 \\
35 \cdot 83 \\
43 \cdot 02\end{array}$ & $\begin{array}{l}6 \cdot 05 \\
0 \cdot 00 \\
7 \cdot 31 \\
8 \cdot 77\end{array}$ & $\begin{array}{l}31 \cdot 01 \\
39 \cdot 43\end{array}$ & $\begin{array}{l}4 \cdot 04 \\
8 \cdot 20\end{array}$ & $<0.01$ \\
\hline $\begin{array}{l}\text { Left posterior } \\
\text { extradural } \\
\text { pressure } \\
70 \mathrm{mmHg}\end{array}$ & $\begin{array}{l}\mathbf{L} \text { anterior } \\
\mathbf{L} \text { posterior } \\
\mathbf{R} \text { anterior } \\
\mathbf{R} \text { posterior }\end{array}$ & $\begin{array}{l}65 \cdot 0 \\
70 \cdot 0 \\
91 \cdot 0 \\
91 \cdot 0\end{array}$ & $\begin{array}{l}79 \cdot 7 \\
70 \cdot 0 \\
81 \cdot 0 \\
96 \cdot 0\end{array}$ & $\begin{array}{l}67 \cdot 5 \\
70 \cdot 0 \\
71 \cdot 0 \\
77 \cdot 5\end{array}$ & $\begin{array}{l}75 \cdot 0 \\
70 \cdot 0 \\
78 \cdot 6 \\
88 \cdot 0\end{array}$ & $\begin{array}{l}57 \cdot 0 \\
70 \cdot 0 \\
58 \cdot 0 \\
82 \cdot 7\end{array}$ & $\begin{array}{l}70 \cdot 0 \\
70 \cdot 0 \\
92 \cdot 0 \\
95 \cdot 0\end{array}$ & $\begin{array}{l}69 \cdot 03 \\
70 \cdot 00 \\
78 \cdot 60 \\
88 \cdot 37\end{array}$ & $\begin{array}{r}7 \cdot 92 \\
0 \cdot 00 \\
12 \cdot 82 \\
7 \cdot 20\end{array}$ & $\begin{array}{l}69 \cdot 52 \\
83 \cdot 49\end{array}$ & $\begin{array}{r}5 \cdot 14 \\
10 \cdot 67\end{array}$ & $<0.001$ \\
\hline $\begin{array}{l}\text { Peak level } \\
\text { left posterior } \\
\text { extradural } \\
\text { pressure }\end{array}$ & $\begin{array}{l}\mathbf{L} \text { anterior } \\
\mathbf{L} \text { posterior } \\
\mathbf{R} \text { anterior } \\
\mathbf{R} \text { posterior }\end{array}$ & $\begin{array}{r}83 \cdot 0 \\
86 \cdot 0 \\
104 \cdot 0 \\
116 \cdot 0\end{array}$ & $\begin{array}{l}132 \cdot 0 \\
113 \cdot 0 \\
127 \cdot 0 \\
164 \cdot 0\end{array}$ & $\begin{array}{l}190 \cdot 0 \\
189 \cdot 0 \\
197 \cdot 0 \\
207 \cdot 0\end{array}$ & $\begin{array}{r}80 \cdot 0 \\
84 \cdot 0 \\
100 \cdot 0 \\
160 \cdot 0\end{array}$ & $\begin{array}{r}80 \cdot 0 \\
104 \cdot 0 \\
86 \cdot 0 \\
113 \cdot 0\end{array}$ & $\begin{array}{l}153 \cdot 0 \\
149 \cdot 0 \\
192 \cdot 0 \\
200 \cdot 0\end{array}$ & $\begin{array}{l}119 \cdot 67 \\
120 \cdot 83 \\
134 \cdot 33 \\
160 \cdot 00\end{array}$ & $\begin{array}{l}46 \cdot 26 \\
40 \cdot 88 \\
48 \cdot 46\end{array}$ & $\begin{array}{l}120 \cdot 25 \\
147 \cdot 17\end{array}$ & $\begin{array}{l}39 \cdot 85 \\
42 \cdot 51\end{array}$ & $<0.01$ \\
\hline
\end{tabular}

* Extradural pressure in mmHg. 
reference. It was thereafter unsatisfactory to use the cisternal reference, since this pressure recording invariably failed at some stage during the development of the experiment. The left posterior transducer, that is, the one furthest away from the balloon on the opposite side of the falx, was thereafter chosen as the reference. Another comparison was made when this reference transducer recorded a level of $30 \mathrm{mmHg}$, again at $70 \mathrm{mmHg}$, and finally when the intracranial pressures had reached their peak and blood flows were very low or absent.

Early in the development of the experiment, with the cisternal pressures recording $10 \mathrm{mmHg}$, there was no significant difference between the recordings from the four transducer sites considered individually. The right posterior transducer anterior to the area of the balloon insertion usually recorded slightly higher values than the rest, the mean being $12.42 \mathrm{mmHg}$ compared with the other means of $9 \mathrm{mmHg}$ for the left posterior, $7.75 \mathrm{mmHg}$ for the left anterior and 8.17 for the right anterior, but these differences were not significant. The hemispheral mean pressures at basal level, $8.83 \mathrm{mmHg}$ (SD $\pm 2 \cdot 14$ ) for the left hemisphere, and $10.30 \mathrm{mmHg}$ (SD \pm 3.89 ) for the right hemisphere, were also not significantly different.

By the time the left posterior or reference transducer had reached $30 \mathrm{mmHg}$, the difference between the right and left-sided transducer pressures had reached significant levels, the right-sided mean being $39.43 \mathrm{mmHg}$ (SD \pm 8.2 ) and the left-sided mean $31.01 \mathrm{mmHg}$ (SD \pm 4.0$)$. The difference between the two was significant $(P<0.01)$. As the intracranial pressure continued to rise, reaching the left posterior reference of $70 \mathrm{mmHg}$, differences between the two sides increased. Thus, the mean left-sided extradural pressure of $69.52 \mathrm{mmHg}(\mathrm{SD} \pm 5 \cdot 1)$ and the mean right-sided pressure of $83.49 \mathrm{mmHg}(\mathrm{SD} \pm 10.7)$ were significantly different at the $\mathbf{P}<0.001$ level. As pressures approached peak values and clearance levels declined, there remained significantly different pressure levels on the two sides: mean left-sided pressure of $120.25 \mathrm{mmHg}(\mathrm{SD} \pm 39.9)$ comparing with mean right-sided pressure of $147 \cdot 17 \mathrm{mmHg}$ (SD $\pm 42 \cdot 5$ ), with $P<0.01$. It is interesting that, though the right posterior transducer invariably recorded higher pressure than the others, the scatter of the data meant that a statistically significant gradient between this and the others could not be obtained. It did not prevent the clear demonstration, however, that the pressures in the supratentorial compartment on the side of the balloon became significantly higher than those on the opposite side of the falx.

In one experiment (P.F.B. 3), the position of the balloon was slightly different from the other five; what was intended as a strictly parieto-occipital placement on the right side developed in the course of the experiment into a mainly right-sided placement, with some extension across the midline behind the sagittal sinus. The figures for this experiment, which are included in the general table, are of interest in that the differences between the rightsided transducers and the left-sided transducers are somewhat lower than in the other experiments.

EFFECTS OF EXTRADURAL EXPANDING LESION ON BLOOD FLOW The effect of the gradually expanding extradural lesion in the right parieto-occipital zone on blood flow in the two halves of the supratentorial compartment is summarized in Table 2. Although

TABLE 2

FLOW DATA

\begin{tabular}{|c|c|c|c|c|c|c|c|c|}
\hline \multirow[t]{3}{*}{ Experiment } & \multicolumn{8}{|c|}{$\begin{array}{l}\text { ICP level (LPE-D transducer }) \\
(\text { flow in } \mathrm{ml} / 100 \mathrm{~g} / \mathrm{min})\end{array}$} \\
\hline & \multicolumn{2}{|c|}{$10 \mathrm{mmHg}$} & \multicolumn{2}{|c|}{$30 \mathrm{mmHg}$} & \multicolumn{2}{|c|}{$70 \mathrm{~mm} \mathrm{Hg}$} & \multicolumn{2}{|c|}{ Peak } \\
\hline & Left & Right & Left & Right & Left & Right & Left & Righn \\
\hline 1 & 80.6 & $99 \cdot 0$ & $69 \cdot 3$ & $75 \cdot 3$ & $83 \cdot 4$ & $83 \cdot 4$ & $11 \cdot 0$ & عُو.6 \\
\hline 2 & $75 \cdot 3$ & $57 \cdot 7$ & 63.0 & $57 \cdot 7$ & $26 \cdot 6$ & $3 \cdot 4$ & 8.7 & $2 \cdot \mathrm{T}$ \\
\hline 3 & $73 \cdot 8$ & 76.0 & $80 \cdot 6$ & 84.9 & $77 \cdot 0$ & $73 \cdot 8$ & 15.4 & $10 \cdot 0$ \\
\hline 4 & $99 \cdot 0$ & 73.8 & 86.6 & $69 \cdot 3$ & 86.6 & $57 \cdot 7$ & $71 \cdot 7$ & $49 \cdot 50$ \\
\hline 5 & 63.0 & $76 \cdot 2$ & $86 \cdot 6$ & $53 \cdot 3$ & $69 \cdot 3$ & $46 \cdot 2$ & $33 \cdot 0$ & $10 \cdot \overline{0}$ \\
\hline 6 & $69 \cdot 3$ & $86 \cdot 6$ & $78 \cdot 7$ & $57 \cdot 7$ & $78 \cdot 7$ & $69 \cdot 3$ & $31 \cdot 5$ & $23 \cdot \frac{1}{\bar{Q}}$ \\
\hline Mean & $76 \cdot 8$ & $78 \cdot 2$ & $77 \cdot 5$ & 66.4 & $69 \cdot 6$ & $55 \cdot 6$ & $28 \cdot 6$ & 17.8? \\
\hline SD & $12 \cdot 4$ & $13 \cdot 8$ & $9 \cdot 5$ & $12 \cdot 3$ & $22 \cdot 3$ & $28 \cdot 7$ & $23 \cdot 5$ & $17 \cdot 3$ \\
\hline $\mathbf{P}$ & $>0$ & .05 & $>0$ & .05 & $<0$ & 05 & $<0$ & .05 \\
\hline
\end{tabular}

anterior and posterior cortical hydrogen electrodes were placed in both hemispheres, anterior placements only have been used in the comparison of the cortical blood flows in the current table, since the right posterior electrode failed in a sufficiently large number of instances to prevent meaningful analysis of the data. Deep electrode placements will be analysed in a later paper. Values for cortical blood flow were values from the fast component unless a monoexponential curve was obtained, when the mean blood flow gave values similar to that of the fast component (Pasztor et al., 1973). The initial values in the two hemispheres were similar, a mean flow of $76.8 \mathrm{ml} / 100 \mathrm{~g} / \mathrm{min}(\mathrm{SD} \pm 12.4)$ for the left hemisphere and $78.2 \mathrm{ml} / 100 \mathrm{~g} / \mathrm{min}(\mathrm{SD} \pm 13.8)$ for $\mathrm{N}$ the right hemisphere being obtained. At an intracranial pressure of $30 \mathrm{mmHg}$, although the hemispheral blood flow on the right had fallen to 66.4 $\mathrm{ml} / 100 \mathrm{~g} / \mathrm{min}(\mathrm{SD} \pm 12 \cdot 3)$, this was neither signifi- 
cantly different from the control value nor from the left hemispheral value of $77.5 \mathrm{ml} / 100 \mathrm{~g} / \mathrm{min}$ (SD \pm 9.5 ). By the time the intracranial pressure had reached $70 \mathrm{mmHg}$, blood flow in both hemispheres had shown a slight fall, the left to $69.6 \mathrm{ml} / 100 \mathrm{~g} /$ $\min (\mathrm{SD} \pm 22 \cdot 3$ ) and the right to $55.6 \mathrm{ml} / 100 \mathrm{~g} / \mathrm{min}$ (SD $\pm 28 \cdot 7)$. The difference between the left hemispheral blood flow at $70 \mathrm{mmHg}$ and control was still not significant, but a significant difference at the $5 \%$ level had appeared between the right and left hemispheres, and the right hemisphere had now significantly lower blood flow than its own control values, again at the $5 \%$ level. At peak level of intracranial pressure, when the clearance on the right hemisphere had reached very low levels, an average mean blood flow on the right of $17.8 \mathrm{ml} / 100 \mathrm{~g} / \mathrm{min}$ (SD $\pm 17 \cdot 3$ ) had been reached. Blood flow in the left hemisphere had by now also declined to a mean of $28.6 \mathrm{ml} /$ $100 \mathrm{~g} / \mathrm{min}$ (SD \pm 23.5 ), significantly different at the $\mathbf{P}<0.05$ level from the flow in the right. In both instances also, there was a highly significant difference $(\mathrm{P}<0.01)$ between the peak blood flow in the two hemispheres and control levels on each side.

EFFECTS OF EXTRADURAL SPACE OCCUPATION ON PERFUSION PRESSURE Perfusion pressure was calculated as the difference between mean systemic blood

TABLE 3

PERFUSION PRESSURE DATA

\begin{tabular}{|c|c|c|c|c|c|c|c|c|}
\hline \multirow[t]{3}{*}{$\begin{array}{l}\text { Experi- } \\
\text { ment }\end{array}$} & \multicolumn{8}{|c|}{$\begin{array}{l}\text { ICP level (LPE-D transducer) } \\
\text { (perfusion pressure in } \mathrm{mmHg})\end{array}$} \\
\hline & \multicolumn{2}{|c|}{$10 \mathrm{mmHg}$} & \multicolumn{2}{|c|}{$30 \mathrm{mmHg}$} & \multicolumn{2}{|c|}{$70 \mathrm{mmHg}$} & \multicolumn{2}{|c|}{ Peak } \\
\hline & Left & Right & Left & Right & Left & Right & Left & Right \\
\hline 1 & 96 & 94 & 86 & 76 & 105 & 82 & 45 & 20 \\
\hline 2 & 91 & 91 & 93 & 91 & 87 & $77 \cdot 5$ & 51 & 22 \\
\hline 3 & 101 & 100 & 125 & 120 & 57 & 43 & 18 & 9 \\
\hline 4 & 106 & 106 & 84 & 73 & 50 & 38 & 44 & 26 \\
\hline 5 & 126 & 126 & 122 & 123 & 71 & 68 & 28 & 20 \\
\hline 6 & 98 & 97 & 109 & 101 & 52 & 42 & 37 & 0 \\
\hline Mean & 103.0 & $102 \cdot 3$ & $103 \cdot 2$ & $97 \cdot 3$ & $70 \cdot 3$ & $58 \cdot 4$ & $37 \cdot 3$ & $16 \cdot 2$ \\
\hline $\begin{array}{l}\text { SD } \\
\mathbf{P}\end{array}$ & $\begin{array}{r}12 \cdot 33 \\
>0\end{array}$ & 12.69 & $\begin{array}{r}18 \cdot 06 \\
<0\end{array}$ & 0.05 & $\begin{array}{r}21 \cdot 94 \\
<0 .\end{array}$ & $\begin{array}{l}19 \cdot 68 \\
.01\end{array}$ & $\begin{array}{r}12 \cdot 25 \\
<0\end{array}$ & $0 \cdot 01$ \\
\hline
\end{tabular}

pressure and average supratentorial compartment pressure on each side, the mean of anterior and posterior extradural pressures being used to calculate each average supratentorial compartment pressure at any given time (Table 3 ). The initial perfusion pressure was similar on the two sides of the head, being $102.3 \mathrm{mmHg}(\mathrm{SD} \pm 12.7)$ on the right, and 103 $\mathrm{mmHg}(\mathrm{SD} \pm 12 \cdot 3)$ on the left. This basal level corresponded to $10 \mathrm{mmHg}$ level from the cisternal pressure transducer and represents the same point as extradural pressure records at this level in Table 1 . As intracranial pressure rose to $30 \mathrm{mmHg}$, measured from the left posterior transducer, perfusion pressure on the right side of the head fell to $97.3 \mathrm{mmHg}$ (SD $\pm 21 \cdot 3$ ), while that on the left remained unchanged at $103.2 \mathrm{mmHg}(\mathrm{SD} \pm 18 \cdot 1)$. This was already a significant deviation from normal on the right side $(P<0.05)$ and there was a significant difference between the two hemispheres again at the $5 \%$ level. By the time the intracranial pressure at the left posterior transducer had risen to $70 \mathrm{mmHg}$, a wider gap in available perfusion pressure had appeared. On the right, perfusion pressure had fallen to 58.4 (SD $\pm 19 \cdot 7)$ and that on the left had also fallen to $70 \cdot 3$ $\mathrm{mmHg}$ (SD \pm 21.9 ). Differences between the two hemispheres were now significant at $P<0.01$, and both were significantly different from the resting level $(P<0.01)$. As peak intracranial pressure was reached, perfusion pressure levels of $16 \mathrm{mmHg}$ (SD $\pm 9.7)$ were obtained from the right hemisphere, and $37 \cdot 2 \mathrm{mmHg}$ (SD $\pm 12 \cdot 2$ ) for the left, the differences again remaining significant at the $\mathrm{P}<0.01$ level.

EVIDENCE OF INTRACRANIAL SHIFTS DURING PARIETOOCCIPITAL BALLOON INFLATION The shift induced by the expanded balloon was checked in each instance by fixation of the head after the death of the animal, the balloon being inflated at the time. There were minor differences in the extent of intracranial shifts produced, largely dependent upon minor variations in the siting of the extradural lesion, but in only one of the experiments were these differences of any significance. This was in experiment P.F.B. 3, in which the balloon had crossed the sagittal sinus and produced a lesser extradural expansion in the left hemisphere. As a result of this, the midline shift induced in this experiment was slightly less than in the other experiments, but basic characteristics were otherwise the same.

Typical displacements are shown in Figs 3 to 5 , taken from the same experiment (P.F.B. 1). The balloon, whose volume was between 6 and $8 \mathrm{ml}$ fully inflated, induced great depression in the posterior parietal and occipital regions centred just in front of the lunate sulcus, not crossing the midline, clearly not obstructing the sagittal sinus, and producing a conspicuous herniation of the posterior part of the hippocampal gyrus and the associated temporal lobe through the posterior part of the tentorial hiatus (Fig. 4). In some experiments, a lesser contralateral herniation was also observable at this point. As shown in Fig. 5, in addition to the foraminal hernia, appreciable herniation of the posterior part of the cingulate gyrus beneath the falx 


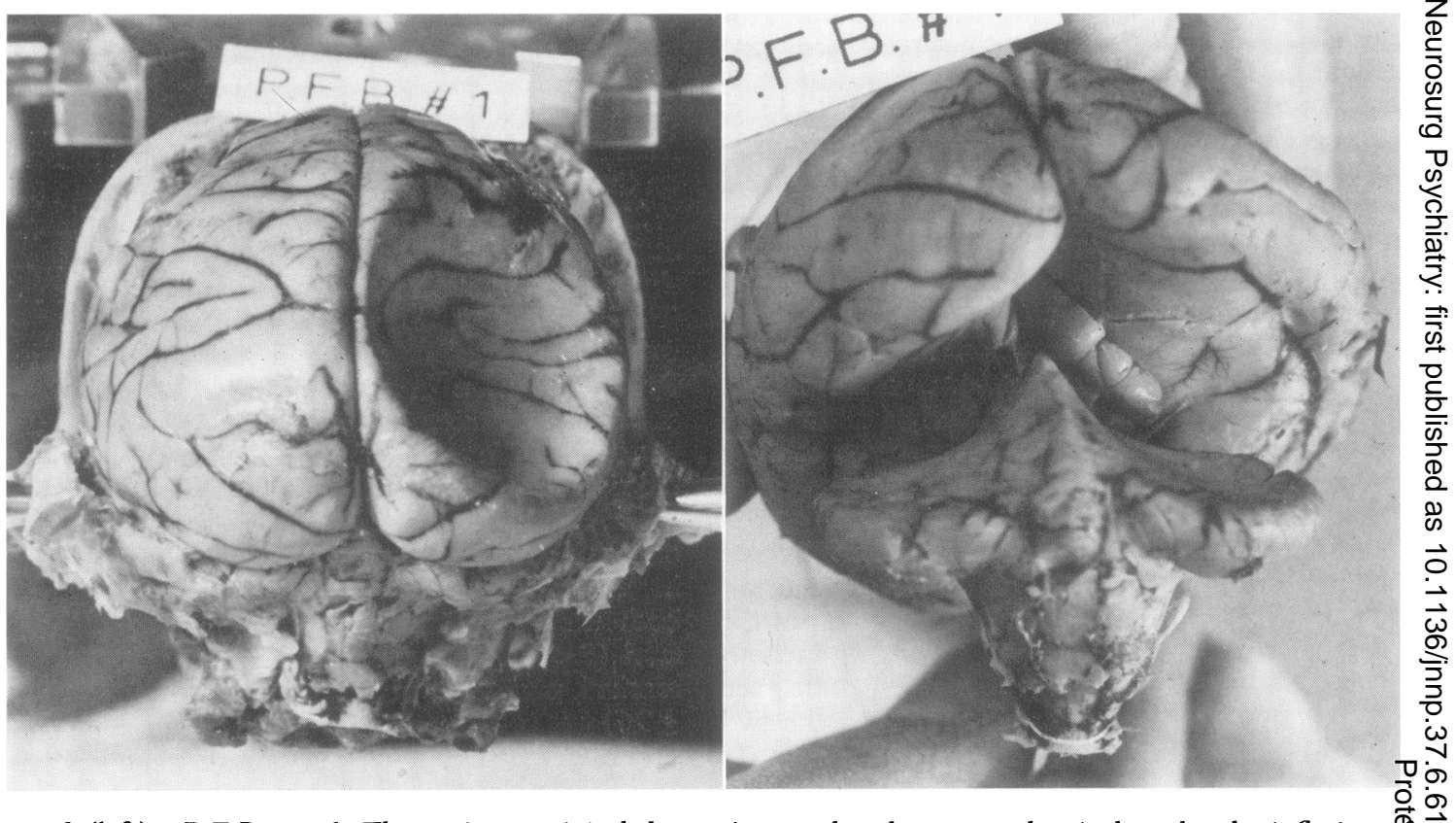

FIG. 3 (left) P.F.B. no. 1. The parieto-occipital depression produced over one hemisphere by the inflation of $\vec{\nabla}$ an extradural balloon (volume $8 \mathrm{ml}$ ).

FIG. 4 (right) P.F.B. no. 1. Downward depression of the right uncus, depression of the tentorial surface of the $\vec{C}$ cerebellum, and herniation of both cerebellar tonsils induced by extradural balloon inflation.

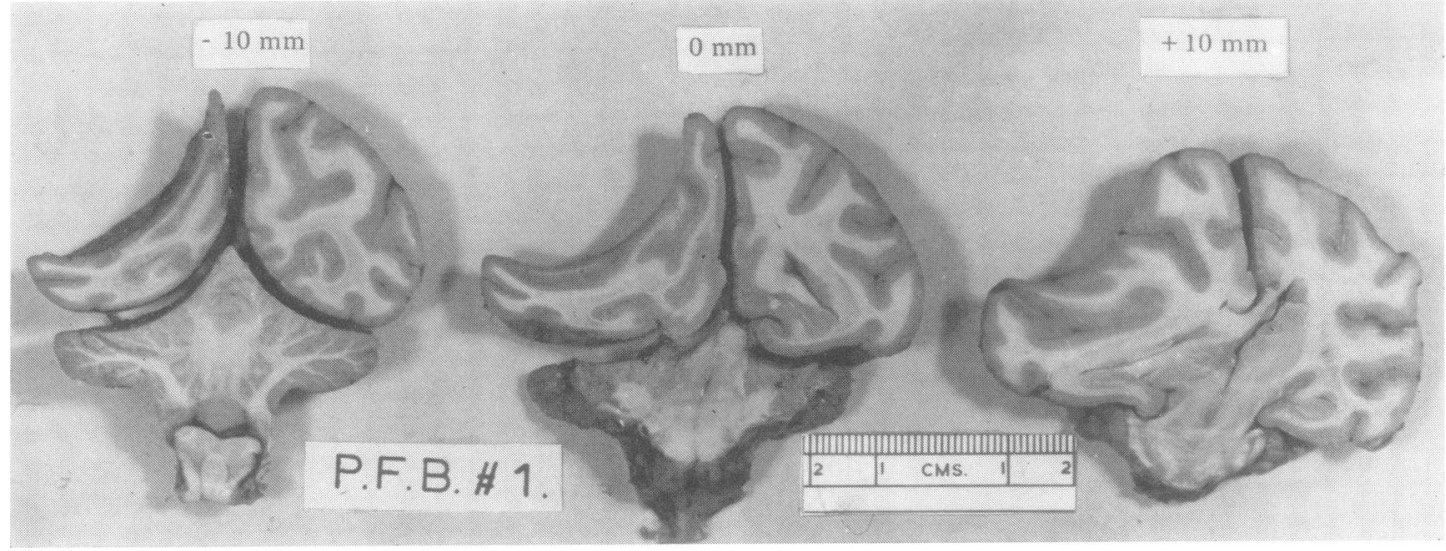

FIG. 5. P.F.B. no. 1. Coronal sections of the hemispheres, cerebellum, and brain-stem in an animal killed with $\mathrm{N}$ maximal inflation of an extradural balloon in the parieto-occipital zone. The brain was fixed in situ. The $\mathfrak{W}^{2}$ references in millimetres are to distances posterior (negative distance) and anterior (positive distances) to the external auditory meatus, the point of fixation in the stereotaxic apparatus. 
was evident, and the posterior part of the thalamus, diencephalon and upper brain-stem was conspicuously deviated across the midline. The whole ventricular system was flattened and displaced to the left. The cerebellar tonsils were bilaterally herniated downwards as shown in Fig. 4, and there was no evidence of particular laterality about the posterior fossa displacements. It is interesting that in all the animals, appreciable down-curving of the tentorium had taken place, with the development of a notably concave upper surface to the cerebellum, the vermis being retained as a sharp peak.

The distortions in Figs 3-5 represent the situation in the hemisphere at the time of peak recording of intracranial pressure and blood flow, when quite demonstrable and significant differences in the supratentorial compartment pressures were evident, when perfusion pressure in the two hemispheres was significantly different, and when there was significantly lower blood flow in the right hemisphere than in the left.

\section{DISCUSSION}

It is only in recent years with the development of the Xenon clearance technique (Lassen et al., 1963; Høedt-Rasmussen et al., 1966; HøedtRasmussen, 1967) and its use in man that the wide variations in regional cerebral blood flow from one area of brain to the next have been appreciated. A study of regional changes in the much smaller primate brain has been less easy to obtain in absolute terms, since the collimation of the Xenon clearance technique makes multiple regional recording difficult, and since the continuous recording methods of heat clearance are difficult to quantitate. The development of the hydrogen clearance technique by Aukland and his associates (Aukland et al., 1964; Aukland, 1965), and its modification in our laboratory (Pasztor et al., 1973; Symon et al., 1973) have enabled us to record blood flow in discrete areas of the primate hemisphere and to compare supratentorial cortical flow between one hemisphere and the other without any possibility of contamination either from extracerebral sources or from grey matter of the opposite side or deep grey matter in the same hemisphere.

While developments in blood flow methodology have reached the stage of fairly widespread acceptance, measurement of intracranial pressures in the various portions of the intracranial space has had less wide documentation and debate continues as to how far the various techniques of measurements may yield comparable results. Several groups have presented data (Dorsch and Symon, 1972; Majors et al., 1972; Sundbärg and Nornes, 1972; Tindall et al., 1972) to show that in conditions of low and moderate intracranial pressure, extradural pressure and central CSF space pressure (cisternal or ventricular) yield identical recordings, but that in circumstances of high intracranial pressure extradural recording with a coplanar device will yield consistently higher pressures, indicating that it is at this stage measuring a component of actual tissue pressure transmitted from the brain held under tension by the elastic pia mater itself. To discuss the potential of coplanar measurements for dynamic deformation analysis in the brain would be outside the scope of this paper, but has been initiated in the work of Schettini et al. (1971), who were the first to point out the extreme importance of coplanarity in such pressure recordings. The extradural transducer made and used in our laboratory enables recordings to be made with ease at four points in the baboon skull; further miniaturization of the transducer might enable more recordings to be made, but in the present study a four-point placement was sufficient to demonstrate beyond equivocation the development of differential pressures between the supratentorial compartments with a posterior parieto-occipital extradural expanding lesion.

The critical rate of lesion expansion, $0.2 \mathrm{ml}$ per minute, was chosen somewhat arbitrarily to produce the complete evolution of critically raised pressure within a comfortably measurable experimental time, but falls well within the limits demonstrated by Nakatani and Ommaya (1972) who showed that the development of the typical Cushing response was dependent upon the rate of expansion of an epidural balloon above a critical rate which they found to be $0.02 \mathrm{ml}$ per minute in the rhesus monkey. More gradual expansion led to prolongation of the experiment, but if expansion rates were cut down to below $0.02 \mathrm{ml}$. per minute, Nakatani and Ommaya demonstrated that differential pressures between supratentorial and infratentorial compartments did not develop, and the vasopressor response could not be elicited. Our present work demonstrates 
that in the non-compressed hemisphere there is no evidence of dissociation between anterior and posterior pressures, but (although the data are not statistically conclusive) they do suggest that the differential pressure develops in the supratentorial compartment between the posterior and anterior portions of the compartment as the pressure increases. It seems probable, therefore, that the transmission of pressure is from the immediate area of the balloon through the normal hemisphere, then beneath the falx, and diffusely into the opposite hemisphere. Our data suggest that differential pressures are most easily obtained with rapid rates of expansion, again agreeing with the observations of Nakatani and Ommaya (1973). The differential pressures demonstrated in our experiments were associated with shifts which would be regarded as typical of a rapidly expanding supratentorial mass in man: subfalcine herniation, ipsilateral uncal herniation, and, to a lesser extent, contralateral uncal herniation, and bilateral foraminal impaction of the tonsils. The fact that these shifts were in our animals invariably associated with Cushing responses, and with dilatation of the ipsilateral pupil initially, leads us strongly to suppose that the origin of the Cushing response is deformation of the upper brain-stem. Nakatani and Ommaya's observation that very slow rates of expansion of an extradural balloon led to the disappearance both of the Cushing response and of differential pressures between supratentorial and infratentorial compartment is, we feel, strong evidence in this regard also.

A certain volume of work has been presented in recent years (Johnston and Rowan, 1974) which has failed to demonstrate differential pressures between the supratentorial compartments with experimental balloon inflation, and suggesting that the Cushing response has its origin in some central neurogenic mechanism as yet undetermined. It seems, however, beyond doubt that the recording of central CSF space pressure made in such experiments is invariably that of mean intracranial pressure, since, as long as the CSF spaces are in continuity one with the other, the pressures will be instantaneously equalized by fluid transmission. It is possible also that the profound collapse of the ventricular systems, as illustrated for example in Fig. 5, means that at such high levels of intracranial pressure satisfac- tory pressure recording from a fluid transmission system will never be practicable. In this respect, our experiences support this conclusion; the cisternal pressure invariably failed when tonsillar herniation began. It is also probable that the methodology employed in the work of Johnston et al. (1972), with regard to blood flow analysis, is unsuitable for the determination of differential blood flow. The use of even accurately collimated Xenon probes cannot exclude contamination from the opposite hemisphere and even from the base of the skull, and, since the differential flows in our own series were difficult to demonstrate at the $5 \%$ level, we suggest that the additional scatter introduced into the data by such contamination when the Xenon method was employed would make statistically significant differences very difficult to find.

The effect of the expansion of the balloon immediately beneath a Xenon collimator, as in the Glasgow studies, must also cause concern about changes in count rate. If, for example, ao posteriorly placed collimator is trained on the post-parietal region and the balloon is subse표을 quently inflated beneath this collimator to ao volume of $10-14 \mathrm{ml}$ saline (Johnston et al. 1973), the count rate of this detector will decline ه substantially since the tissue to which it is $\overrightarrow{0}$ mainly reactive has been displaced outside the area of maximum sensitivity of the detector. The reliability and significance of flows estimated using this detector will then be questionable compared with those obtained from a comparably placed contralateral probe.

The finding in the present series of experiments that blood flow did not deviate significantly from normal in either hemisphere until an intracranial pressure of over $70 \mathrm{mmHg}$ had been reached is in keeping with our previous demonstration that the autoregulatory characteristics of the baboon cerebral circulation, as assessed by hydrogen clearance, will maintain normal flow to a level of intracranial pressure of this magnitude assuming normal blood pressure in the animal at the time. Indeed, a plot of data from both cortical and deep flow in the present series of experiments showed a curve of autoregulation similar to that obtained in elevation in intracranial pressure by cisternal infusion. In particular, there was no evidence of hyperaemia either in superficial or deep tissues preceding the fall of 
flow induced by a rising perfusion pressure (Symon et al., 1973). In the data from the experiments as a whole it was impossible to separate the curve of autoregulation for the earlier compressed hemisphere from that of the opposite side, but, as Tables 2 and 3 show, the appearance of significant differences in the flow data occurred at the $70 \mathrm{mmHg}$ reference level in the left posterior transducer. At this time, the lesser compressed hemisphere retained a cortical blood flow of $69.6 \mathrm{ml} / 100 \mathrm{~g} / \mathrm{min}$, which was not significantly different from control, and perfusion pressure in this hemisphere was 70.3 $\mathrm{mmHg}$, within the autoregulatory range of the circulation. On the right side, however, the hemisphere beneath the balloon had a perfusion pressure which at $58.4 \mathrm{mmHg}$ is below the level at which one would expect autoregulation to extend in this preparation, and indeed blood flow in the cortex of this hemisphere had fallen to $55 \cdot 6 / \mathrm{ml} / 100 \mathrm{~g} / \mathrm{min}$, significantly different from control values of that hemisphere at the $5 \%$ level, and from the blood flow of the opposite hemisphere at the same level of significance. From this point onwards in the experiment, both hemispheres had perfusion pressures of a level consistent with a passive pressure relationship, so that the continuing difference in flow between the two hemispheres is explicable by the higher intracranial pressure induced in the supratentorial compartment on the side of the balloon, and the correspondingly reduced perfusion pressure in that hemisphere as compared with its fellow. The supratentorial compartmental pressures at the rate of balloon expansion chosen differed by levels sufficiently great to be easily determined by an extradural pressure recording device; even so, these differences were hardly sufficient to exhaust the autoregulatory capacity of the more compressed hemisphere very much before that of the less compressed. The technique of episodic blood flow recording, therefore, may render it quite difficult to pick up depression of flow in one hemisphere significantly before the other hemisphere follows suit, and it is therefore not possible to separate curves of autoregulation for the two hemispheres. It seems that failure o autoregulation in our preparation took place in one hemisphere shortly before the $70 \mathrm{mmHg}$ intracranial pressure was reached at the reference transducer, and in the other hemisphere shortly after this point. Perhaps a more frequent recording of flow by the technique of two minute clearance might resolve this close flow matching.

It is also difficult to resolve events at or about the critical level of failure of autoregulation, in relation to the development of intracranial shifts and of medullary compression. In our own experiments, about the time when intracranial shifts were occurring, as deduced from failure of reaction and beginning of dilatation of the ipsilateral pupil, autoregulation in the ipsilateral hemisphere was beginning to fail, and shortlived Cushing responses were making their presence evident on the systemic blood pressure trace. We suggest that the transmission of the pressure wave to the opposite hemisphere thereafter resulted in a fall in contralateral hemispheric flow, with diencephalic compression and the fully developed Cushing response. Death from mid-brain compression and medullary ischaemia would follow shortly thereafter.

Experimental evidence at this time suggests that a more gradual rate of expansion of supratentorial balloons does not result in the development of such readily demonstrable differential pressures. The explanation probably lies in the astonishing viscoelastic properties of the brain, which enable it to change shape while preserving function within limits; it seems likely that this represents a further adaptive factor in the pressure flow relationship. One would suppose therefore that, with a slower rate of expansion, the failure of autoregulation and critical displacements in the brain-stem would be delayed until a much larger lesion had been accommodated. At a critical stage, however, a slight further incremental expansion might result in the rapid development of differential pressures, excessive shifts, and sudden clinical deterioration. Nevertheless, it has been shown by Dorsch and Symon (1972) and by O'Brien and Waltz (1972) that differential pressures may be recorded even with the relatively slow expansion produced by infarction of one hemisphere. The degree to which the plastic properties of the brain are capable of evening out intra-tissue pressure gradients is a subject which deserves study and which will clearly stimulate methodological advance in the near future. 


\section{REFERENCES}

Aukland, K., Bower, B. F., and Berliner, R. W. (1964). Measurement of local blood flow with hydrogen gas. Circulation Research, 14, 164-187.

Aukland, K. (1965). Hydrogen polarography in measurement of local blood flow; theoretical and empirical basis. In Regional Cerebral Blood Flow, pp. 42-45. Acta Neurologica Scandinavica, S. 14, pp. 42-45.

Corne, S. J., Stephens, R. J., and Symon, L. (1968). The effect of drugs on the intracranial pressure of baboons. British Journal of Pharmacology, Proceedings of the Pharmacological Society, 34, 212P.

Dorsch, N. W. C., Stephens, R. J., and Symon, L. (1971). An intracranial pressure transducer. Biomedical Engineering, 6, 452-457.

Dorsch, N. W. C., and Symon, L. (1972). Intracranial pressure changes in acute ischaemic regions of the primate hemisphere. In Intracranial Pressure, pp. 109-114. Edited by $M$. Brock and H. Dietz. Springer: Berlin.

Høedt-Rasmussen, K., Sveinsdottir, E., and Lassen, N. A. (1966). Regional cerebral blood flow in man determined by intra-arterial injection of radioactive inert gas. Circulation Research, 18, 237-247.

Høedt-Rasmussen, K. (1967). Regional cerebral blood flow. The intra-arterial injection method. Acta Neurologica Scandinavica, 43, Supplement 27.

Hulme, A., and Cooper, R. (1966). A technique for the investigation of intracranial pressure in man. Journal of Neurology, Neurosurgery, and Psychiatry, 29, 154-156.

Jacobson, S. A., and Rothballer, A. B. (1967). Prolonged measurement of experimental intracranial pressure using a subminiature absolute pressure transducer. Journal of Neurosurgery, 26, 603-608.

Johnston, I. H., Rowan, J. O., Harper, A. M., and Jennett, W. B. (1972). Raised intracranial pressure and cerebral blood flow. I. Cisterna magna infusion in primates. Journal of Neurology, Neurosurgery, and Psychiatry, 35, 285-296.

Johnston, I. H., Rowan, J. O., Harper, A. M., and Jennett, W. B. (1973). Raised intracranial pressure and cerebral blood flow. 2. Supratentorial and infratentorial mass lesions in primates. Journal of Neurology, Neurosurgery, and Psychiatry, 36, 161-170.

Johnston, I. H., and Rowan, J. O. (1974). Intracranial pressure gradients in cerebral hemisphere blood flow differences during expansion of unilateral supratentorial mass lesions in primates. In Cerebral Circulation and Metabolism,
Proceedings of the 6th International Cerebral Blood Flow Symposium, Philadelphia, 1973. (In press.)

Langfitt, T. W. (1969). Increased intracranial pressure. Clinical Neurosurgery, 16, 436-471.

Lassen, N. A., Høedt-Rasmussen, K., Sørensen, S. C., Skinhøj, E., Cronquist, S., Bodforss, B., and Ingvar, D. H. (1963). Regional cerebral blood flow in man determined by krypton 85 . Neurology (Minneap.), 13, 719727.

Lundberg, N. (1960). Continuous recording and control of ventricular fluid pressure in neurosurgical practice. Acta Psychiatrica Scandinavica, 36, Supplement 149.

Majors, R., Schettini, A., Mahig, J., and Nevis, A. H. (1972). Intracranial pressures measured with the coplanar pressure transducer. Medical and Biological Engineering, 10, 724 733.

Nakatani, S., and Ommaya, A. K. (1972). A critical rate of cerebral compression. In Intracranial Pressure, pp. 144 148. Edited by M. Brock and H. Dietz. Springer: Berlin.

O'Brien, M. D., and Waltz, A. G. (1972). Intracranial pressure changes during experimental cerebral infarction. In Intracranial Pressure, pp. 105-108. Edited by M. Brock and H. Dietz. Springer: Berlin.

Pasztor, E., Symon, L., Dorsch, N. W. C., and Branston, N. M. (1973). The hydrogen clearance method in assessment of blood flow in cortex, white matter and deep nucle of baboons. Stroke, 4, 556-567.

Schettini, A., McKay, L., Majors, R., Mahig, J., and Nevis, A. H. (1971). Experimental approach for monitoring sur-o face brain pressure. Journal of Neurosurgery, 34, 38-47.

Sundbärg, G., and Nornes, H. (1972). Simultaneous recording of the epidural and ventricular fluid pressure. In Intracranial Pressure, pp. 46-50. Edited by $\mathrm{M}$. Brock and $\mathrm{H}$ Dietz. Springer: Berlin.

Symon, L., Dorsch, N. W. C., and Stephens, R. J. (1972) Pressure waves in so-called low-pressure hydrocephalus. Lancet, 2, 1291-1292.

Symon, L., Pasztor, E., Dorsch, N. W. C., and Branston N. M. (1973). Physiological responses of local areas of the cerebral circulation in experimental primates determined by the method of hydrogen clearance. Stroke, 4, 632-642.

Tindall, G. T., McGraw, C. P., and Iwata, K. (1972). Subdural pressure monitoring in head-injured patients. In Intracranial Pressure, pp. 9-13. Edited by M. Brock and H. Dietz. Springer: Berlin. 